3.- The fluorescein test may apparently show obstruction in cases with no epiphora and therefore is not of great practical importance.

4.- Sterilization of the conjunctival sac as regards streptococci and pneumococci was obtained in 82 per cent.

\title{
REFERENCES
}

1. Quoted by West in "Clinical Results of Intranasal Tear-sac Operation." Trans. Ophthal. Amer. Med. Assoc., pp. 69-81, 1931.

2. Ibid.

3. Kofler and Urbanek.-Zur Vereinfachung und Verbesserung der WestPolyak'schen endonasalen Tränen-sackoperation. Wien. Med. Wochenschr., Vol. LXXVIII, p. 632, 1928.

4. Paterson and Fraser.-Brit. Jl. of Ophthal., May, 1919.

Fraser.--Intranasal Dacryocystostomy. Jl. of Laryngol. and Otol., Vol. XL, pp. 725-729, 1925.

\section{A HAND SLIT-LAMP}

BY

\section{N. BISHOP HARMAN}

LONDON

THE value of the standard forms of slit-lamps for certain ophthalmic investigations is undoubted. But the immobility of these large instruments limits their use to the consulting room and clinic.

The hand slit-lamp shown has been devised with the intent of securing an instrument that could be used as readily and as easily as an electric ophthalmoscope; so that it can be carried about, and used with ease for the examination of children, and patients in bed or in their own homes. It cannot, by reason of its small size, compete with the large instruments in magnification and in resolution of fine detail. Yet it will secure a valuable view of the media of the eye as deep as the anterior part of the vitreous. The small lamp as compared with the large might be said to have something like the relation of two-thirds inch objective of the microscope to the one-sixth inch objective. But the small lamp gives the same effect of depth as the large lamp, so that its value for localization is certain.

The lamp is fitted to the battery handle of an electric ophthalmoscope; or a small adapter can be supplied with leads to a torch battery or other suitable source of current. At the upper end, set at right angles to the ophthalmoscope handle, is an eyepiece consisting of a triple achromatic lens giving a linear magnification of $12 \mathrm{X}$. The lens holder is so made that other powered lenses can be substituted. The case of the eyepiece is graven with a 
scale so that the focus of the lens, once found, can always be recovered.

Below the eyepiece, and at an angle of $45^{\circ}$ to it, is the projection combination, forming a horizontal slit of light at a distance of one inch. It comprises a gas-filled lamp with a single strand filament, made for two-cell or three-cell dry batteries. The centre pole of the lamp abuts on to a spring contact, so that all lamps can be set with the filament horizontal. A powerful condensing system produces an image of the filament upon a slit fixed in the

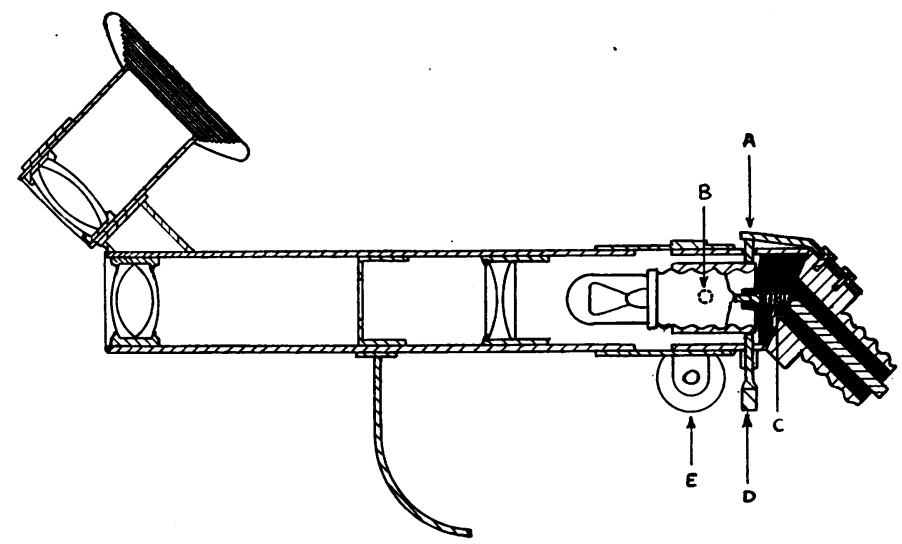

In the diagram, A represents the spring, and D the screw controlling the lamp centre. $B$ indicates the position of the trunnion, $C$ the centre contact of the lamp, and E the clamping screw. Note that in practice the filament and slit are horizontal.

tube, so that the projection lens, an achromatic lens of some 60 dioptres, can form a clear image of this slit, free from disturbing haze or filament irregularities.

In use, the instrument must be kept steady in relation to the eye of the patient, and yet allow focusing for depth. This can be obtained by the following manoeuvre. The lamp is held by the main tube with the battery handle or adapter hanging down. There is a trigger-like spur projecting below the main tube, and this lies conveniently between the second and third fingers. The thumb rests on the top of the tube, with its end in the angle between the tube and eyepiece, the forefinger lies along the side, so that the projecting tip of the finger can rest against the patient's cheek at the lower border of the orbit. This contact gives steady support. Alternate crooking and straightening the forefinger brings the lamp nearer or further from the eye and gives focusing for depth.

Adjustments of the instrument are of the fewest, normally the eyepiece alone is likely to require setting. But the setting of the 
lamp bulb, in case of replacement, needs attention. The filament must be horizontal and in the axis of the system. Whether or no this adjustment is correct, can be seen by looking at the face of the projection lens. The bright line of light should cut the lens horizontally into two equal parts. If this line is not true, the position of the filament must be altered. The lamp mount is pivoted at its front end on a horizontal axis on trunnions. At the back there are a screw and a spring on a vertical axis, the one lifting the back, the other allowing it to fall: As the back rises, so the filament is lowered, and vice versa, the movement being made by releasing or screwing in the lower screw. The distance between the lamp and the condenser system can be varied by loosening the large headed screw under the lamp end of the tube, and allowing the tube to slide over the lamp stem a little. This large-headed screw should be turned firmly when the adjustment has been made. Once the adjustment is obtained, it need not be altered until a new lamp is required.

It is better not to wear spectacles when using the lamp so that one's eye can be well within the shield of the ocular. It is well not to over-run the electric bulb, so when a new battery is used the switch to the rheostat should be turned on no more than twothirds until the battery weakens.

The hand slit-lamp is made by Messrs. Rayner of New Bond Street, London.

\section{A NEW SLIT-LAMP}

BY

E. GORDON MACKIE

SHEFFIELD

THE Slit-lamp has not hitherto been so widely used as its undoubted merits deserve. This is no doubt partly due to its many complicated adjustments which necessarily increase the cost of the apparatus. Quite a number of these are but rarely used in working the lamp, and some of them can be rendered unnecessary and expense saved by improvement in design. Its real value can only be appreciated by regular use and with the hope of inducing more of my colleagues to adopt this aid to their work I venture to bring to their notice the instrument here illustrated.

It has been made in accordance with the above ideas and having now been in use for over eighteen months and satisfied certain experienced slit-lamp observers may be said to be more than an experiment. 